\title{
Relationship between Acculturation Attitude and Effectiveness of Pragmatic Instruction
}

\author{
Vahid Rafieyan \\ International College of Liberal Arts, Yamanashi Gakuin University \\ Kofu, Yamanashi, Japan \\ E-mail: rafieyanv@ygu.ac.jp
}

Received: 01-05- 2016

Accepted: 09-07-2016

Published: 31-07-2016

doi:10.7575/aiac.ijels.v.4n.3p.1

URL: http://dx.doi.org/10.7575/aiac.ijels.v.4n.3p.1

\begin{abstract}
Attitude toward accepting target language culture or maintaining heritage culture referred to as acculturation attitude can determine language learners' pragmatic gains during an educational sojourn. To this end, the current study investigated the relationship between language learners' acculturation attitudes during an educational sojourn and the effectiveness of pragmatic instruction. Participants of the study were 52 Iranian postgraduate students of English education at a university in Australia. A discourse completion task was used to assess language learners' level of pragmatic competence. The adapted version of Berry's (2001) East Asian Acculturation Measure (EAAM) was also used to assess language learners' level of acculturation attitude toward Australian culture. The analysis of Pearson product-moment correlation coefficient ( $r$ ) revealed that there is a strong positive relationship between acculturation attitude and effectiveness of pragmatic instruction. The pedagogical implications of the findings suggested encouraging and providing opportunities for language learners who are on an educational sojourn to immerse in target language culture to be able to develop their pragmatic competence to an optimal level.
\end{abstract}

Keywords: Acculturation Attitude, Pragmatic Competence, Pragmatic Instruction

\section{Introduction}

Pragmatic competence defined as the ability to comprehend and convey one's intention appropriately in social interactions involves one's linguistic knowledge and knowledge of norms of the target culture and the ability to use these knowledge bases when performing social functions (Taguchi, 2015). Since communication over social functions occurs in everyday life situations via interaction with others, educational sojourn, defined as a period spent abroad in a region where a target language is used as a medium of everyday communication (Culhane, 2004), offers an optimal context for the development of pragmatic competence (Taguchi, 2015). However, level of pragmatic gains depends on the tendency of language learners on the educational sojourn to merge into the target culture and use the opportunity to observe and practice pragmatic implications of everyday language use or to stick to their heritage culture. Therefore, attitude toward accepting target language culture or maintaining heritage culture referred to as acculturation attitude, can determine language learners' pragmatic gains during an educational sojourn.

Berry (1980) came up with a model for acculturation attitudes which outlines the various ways that people acculturate. This acculturation attitude model comprises two major dimensions: the degree to which people are willing to keep their heritage culture and the degree to which people are willing to have contact with the people of the target society and adopt the culture of the target society (Figure 1).

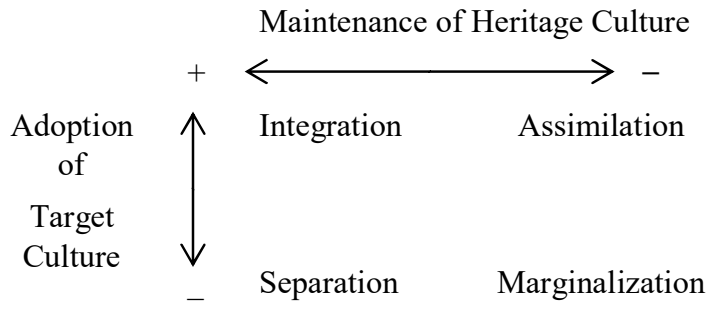

Figure 1. Acculturation Strategies

The degree of willingness toward any of these two dimensions of keeping heritage culture and adopting the culture of the target society results in the adoption of four types of acculturation strategies including: assimilation, integration, 
separation, and marginalization. Assimilation is the acculturation strategy in which people are not willing to keep their heritage culture but are willing to have close contact with the people of the target society and adopt the culture of the target society. Integration is the acculturation strategy in which people both are willing to keep their heritage culture and have close contact with the people of the target society and learn about the culture of the target society. Separation is the acculturation strategy in which people are willing to keep their heritage culture but avoid contact with the people of the target society and the culture of the target society. Marginalization is the acculturation strategy in which people are neither willing to keep their heritage culture nor willing to have contact with the people of the target society and learn about the culture of the target society (Sam \& Berry, 2010).

Research over the relationship between language learners' acculturation attitudes and their target language gains has attracted the attention of scholars during the past decade. In one of these studies, Jiang et al. (2009) explored the significance of the role of acculturation attitude in language learners' pronunciation ability and their speaking proficiency. Participants of their study consisted of a group of Chinese students studying at a university in the United States. The Stephenson Multigroup Acculturation Scale was adopted to examine students' acculturation progress, a sentence reading task was used to examine their pronunciation ability, and a language proficiency interview was used to examine their speaking proficiency. The results of the analysis of the data revealed that students were more immersed in their heritage culture than the target culture but differed in their acculturation toward the target society. The level of immersion in the target society contributed to students' speaking proficiency but did not contribute to their pronunciation ability. In another study, Cara (2010) examined the acculturation strategies of a group of Russians in Latvia both before and after the education reform as well as the relationship between the type of acculturation strategies chosen and knowledge of Latvian language. Knowledge of Latvian language was assessed through a three-item fourpoint scale questionnaire assessing three language skills of speaking, writing, and reading. Acculturation strategy was measured through an acculturation attitude questionnaire assessing four acculturation strategies of assimilation, integration, separation, and marginalization on a four-point scale. The analysis of findings showed that while integration was the most favored acculturation strategy, marginalization was the least favored acculturation strategy both before and after the education reform. Furthermore, while Latvian language knowledge was positively related to assimilation and integration strategies, it was negatively related to separation and marginalization strategies. Waniek-Klimczak (2011) also conducted a research study in order to examine the acculturation attitudes of a group of Polish learners of English who were on an educational sojourn in England. An open-ended questionnaire comprising items related to both language learners' acculturation strategies and their language experience was used to collect data qualitatively. The analysis of the findings revealed that Polish language learners of English adopted both assimilation and integration as their acculturation strategies. Furthermore, language learners mentioned that formal training which they had received in language classes was not as effective as exposure to authentic culturally specific materials. Taguchi (2015) was the other researcher who investigated the relationship between language learners' entry-level cross-cultural adaptability and their gains in pragmatic competence in study abroad. Participants were a group of international students enrolled in a Japanese language program in a university in Japan. Cross-cultural adaptability was assessed with the Cross-Cultural Adaptability Inventory (CCAI) developed by Kelley and Meyers (1995). An oral discourse completion test was also used to measure speech act production. The study found that cross-cultural adaptability was significantly related to the development of pragmatic competence. Rafieyan et al. (2015a) also conducted a study to investigate the relationship between acculturation attitude and pragmatic comprehension. Participants of the study consisted of a group of Iranian undergraduate students of English in universities in Australia. Data were collected through a Likert scale acculturation attitude questionnaire and a multiple choice pragmatic comprehension test. The study found that there is a strong positive relationship between the degree of acculturation attitude toward target language culture and the pragmatic comprehension ability. Most recently, Rafieyan (2016) explored the relationship between language learners' acculturation attitudes and the quality of their translation of culture-bound texts. Participants of the study were a group of Iranian postgraduate students of English translation at universities in England. Data were collected through the modified version of the East Asian Acculturation Measure developed by Berry (2001) to test participants' acculturation attitudes and a culture-bound text adopted from The British Broadcasting Corporation (BBC) to test their translation quality. The results of the correlation analysis indicated a strong positive relationship between acculturation attitude and quality of translation of culture-bound texts.

The studies conducted so far have investigated the relationship between language learners' acculturation attitudes and their general language proficiency and pragmatic competence. These studies have revealed a significant positive relationship between immersion in target language culture and both linguistic and pragmatic development. However, because of the paucity of existing findings, more studies are needed to test the relationship between acculturation attitude and pragmatic competence (Taguchi, 2015). In this regard, the current study seeks to investigate the relationship between language learners' acculturation attitudes during an educational sojourn and the effectiveness of pragmatic instruction. Therefore, the research question to be addressed in the current study is:

Is there any relationship between acculturation attitude and effectiveness of pragmatic instruction?

Accordingly the null hypothesis is:

There is no relationship between acculturation attitude and effectiveness of pragmatic instruction. 


\section{Method}

\subsection{Participants}

Participants of the study were 52 (32 females \& 20 males) Iranian students at a university in Australia. All participants were postgraduate students of English education studying for a Master's degree. Since their Bachelor's degree was in English and they had an IELTS overall band of minimum 6.5 as the entry requirement for the university, they were considered to be at a high level of English proficiency. The reason for inclusion of highly proficient language learners in the study was assuring that mistakes are merely attributed to pragmatic knowledge and not linguistic deficiency. Their length of residence in Australia also ranged from 10 to 18 months. Therefore, they were in Australia long enough to be sufficiently exposed to target language culture.

\subsection{Instruments}

To assess language learners' level of pragmatic competence, a discourse completion task eliciting a variety of speech acts including expressions of gratitude, apologies, warnings, leave-takings, requests, condolences, declining offers, acceptance of a request, acceptance of an invitation, invitation, declining an invitation, an agreement, deflecting thanks, and an introduction developed by Bardovi-Harlig (2009) was adopted. The discourse completion task consisted of 32 scenarios comprising both initiating and responding scenarios. The initiating scenarios $(n=13)$ required language learners to initiate an interaction and the responding scenarios $(n=19)$ required language learners to respond to an interlocutor's turn.

To assess language learners' level of acculturation attitude toward Australian culture, the East Asian Acculturation Measure (EAAM), developed by Berry (2001), was adapted. The questionnaire consisted of 29 items with four subscales: assimilation attitude (items 1-8), integration attitude (items 9-13), separation attitude (items 14-20), and marginalization attitude (items 21-29). The items were based on a Likert scale ranging from strongly disagree to strongly agree with values 1 to 5 assigned to them respectively. In this respect, the value of 1 was assigned to 'strongly disagree', the value of 2 was assigned to 'disagree', the value of 3 was assigned to 'neutral', the value of 4 was assigned to 'agree', and the value of 5 was assigned to 'strongly agree'. The original questionnaire had been designed for a group of Asians including Chinese, Japanese, and Korean immigrants to America. In the adapted version of the questionnaire 'Asian' was replaced by 'Iranian' and 'American' was replaced by ‘Australian'.

\subsection{Procedure}

Since the beginning of the fall semester in the academic year 2015/2016, pragmatic features of Australian language (pragmalinguistics) and culture (sociopragmatics) were incorporated in the usual class instruction of four core subjects of the language learners. As part of class instruction, language learners were instructed on both pragmalinguistic and sociopragmatic rules of appropriate communication in Australia. Around 10 minutes of each session was allocated to pragmatic instruction. Pragmatic instruction continued for the whole semester. Then, at the end of the semester, the pragmatic test was administered to language learners participating in the study. They were instructed to read each scenario and express whatever initially comes to their minds by writing to respond to each scenario within few words. Following the completion of the pragmatic test, the acculturation attitude questionnaire was administered to all language learners. Language learners were asked to reflect on the idea expressed by each item on the questionnaire and express their attitudes toward each item by circling the rating on the scale which best reflected their opinion. At the end, the slips of both tests were collected for the subsequent analysis.

\subsection{Data Analysis}

To assess language learners' level of pragmatic competence, the appropriateness of the responses to the discourse completion task was assessed by two native speakers of English using a four-point rating scale ranging from zero (cannot evaluate) to three (native-like). The ratings along with the description for each band on the scale have been provided in Table 1. As there were 32 scenarios, each participant could get a mark ranging from 0 to 96 . In this respect, language learners who obtained a mark of 0 were placed at the level of 'cannot evaluate', language learners who obtained a mark between 1 and 32 were placed at the level of 'obviously off', language learners who obtained a mark between 33 and 64 were placed at the level of 'slightly off, but acceptable', and language learners who obtained a mark between 65 and 96 were placed at the level of 'native-like'.

Table 1. Description of Ratings for Pragmatic Competence

\begin{tabular}{lll}
\hline Rating & Band & Descriptions \\
\hline 3 & Native-like & $\begin{array}{l}\text { The utterance is almost perfectly appropriate. This is what a native speaker would } \\
\text { usually say in the situation }\end{array}$ \\
2 & $\begin{array}{l}\text { Slightly off, but } \\
\text { acceptable }\end{array}$ & $\begin{array}{l}\text { The utterance is a little off from native-like due to minor grammatical and lexical } \\
\text { errors but overall acceptable }\end{array}$ \\
1 & Obviously off & $\begin{array}{l}\text { The utterance is clearly non-native like because of strange, non-typical way of } \\
\text { saying and/or major grammatical and lexical errors }\end{array}$ \\
0 & Can't evaluate & The utterance is impossible to understand
\end{tabular}

Adopted from Taguchi (2013) 
The degree of agreement between the ratings assigned by the two native speakers of English was then assessed through Cohen's Kappa which is a measure of inter-rater reliability used to measure agreement between two coders (Saldanha \& O'Brien, 2014). The analysis of Cohen's Kappa would give a value between -1 and +1 . The interpretation of the values obtained through Cohen's Kappa, according to Landis and Koch (1977), are presented in Table 2. The inter-rater reliability assessed for the responses to the discourse completion task was 0.82 which, according to the guidelines set by Landis and Koch (1977), indicates an almost perfect agreement between the two raters. For cases which received different ratings, the two native speakers of English discussed until they reached an agreement.

Table 2. Interpretation of Cohen's Kappa Values

\begin{tabular}{ll}
\hline Values & Interpretation \\
\hline Smaller than 0.00 & Poor Agreement \\
0.00 to 0.20 & Slight Agreement \\
0.21 to 0.40 & Fair Agreement \\
0.41 to 0.60 & Moderate Agreement \\
0.61 to 0.80 & Substantial Agreement \\
0.81 to 1.00 & Almost Perfect Agreement \\
\hline
\end{tabular}

To measure acculturation attitude of language learners, descriptive statistics was used to describe and summarize the properties of the data collected from the language learners. Descriptive statistics consisted mainly of mean and standard deviation. The acculturation attitude was represented by a mean score on a 5-point scale, where 1 (strongly disagree) represented the minimum score on the scale and 5 (strongly agree) represented the maximum score on the scale. The overall mean score for each acculturation strategy determined language learners' level of attitude regarding that specific strategy. The acculturation strategy which received the highest mean score represented language learners' acculturation attitude. For the purpose of correlation analysis, higher values were assigned to the acculturation strategies which represented a higher attitude toward target culture and lower values were assigned to the acculturation strategies which represented a higher attitude toward heritage culture. In this respect, the value of 1 was assigned to 'marginalization attitude', the value of 2 was assigned to 'separation attitude', the value of 3 was assigned to 'integration attitude', and the value of 4 was assigned to 'assimilation attitude'.

To assess the relationship between acculturation attitude and pragmatic competence, Pearson product-moment correlation coefficient ( $\mathrm{r}$ ), which is used to describe the strength and direction of the linear relationship between two continuous variables (Gravetter \& Wallnau, 2013), was computed. Pearson correlation coefficient can only take on values from -1 to +1 . The sign out the front indicates whether there is a positive correlation (as one variable increases, so too does the other) or a negative correlation (as one variable increases, the other decreases). The size of the absolute value (ignoring the sign) provides an indication of the strength of the relationship. A perfect correlation of +1 or -1 indicates that the value of one variable can be determined exactly by knowing the value on the other variable. On the other hand, a correlation of 0 indicates no relationship between the two variables. Knowing the value on one of the variables provides no assistance in predicting the value on the second variable (Pallant, 2013). Cohen (1988) suggests a set of guidelines to interpret the values between 0.00 and 1.00. The guidelines, which have been presented in Table 3 , apply whether or not there is a negative sign out the front of the $r$ value.

Table 3. Strength of Relationship

\begin{tabular}{ll}
\hline $\mathrm{r}$ Value & Interpretation \\
\hline $0.10-0.29$ & Small Correlation \\
$0.30-0.49$ & Medium Correlation \\
$0.50-1.00$ & Large Correlation \\
\hline
\end{tabular}

The squared correlation $\left(\mathrm{r}^{2}\right)$, called the coefficient of determination, was then used to measure the proportion of variability in level of pragmatic competence that can be determined from its relationship with acculturation attitude. Squared correlation would give a value ranging from 0.00 to 1.00. Cohen (1988) has also suggested a set of guidelines to interpret the values of squared correlation. The criterion for interpreting the value of squared correlation $\left(\mathrm{r}^{2}\right)$, as proposed by Cohen (1988), has been presented in Table 4. 


\begin{tabular}{ll}
\hline Table 4. Percentage of Variance Explained, $\mathrm{r}^{2}$ & \\
\hline $\mathrm{r}^{2}$ Value & Interpretation \\
\hline 0.01 & Small Correlation \\
0.09 & Medium Correlation \\
0.25 & Large Correlation \\
\hline
\end{tabular}

\section{Results}

Table 5 presents the descriptive presentation of level of pragmatic competence of language learners participating in the study. Descriptive data presented in the table consists of the number and percentage of participants in each level of pragmatic competence. According to the descriptive data, the majority of participants presented their pragmatic competence at a satisfactory level (84.61 percent). As the data shows, 21.15 percent of participants presented their pragmatic competence at a high level ('native-like' level), 63.46 percent of participants presented their pragmatic competence at an acceptable level ('slightly off, but acceptable' level), and 15.39 percent of participants presented their pragmatic competence at a low level ('obviously off' level). None of the participants, however, presented pragmatic competence at a 'cannot evaluate' level.

Table 5. Descriptive Presentation of Levels of Pragmatic Competence

\begin{tabular}{lcc}
\hline Levels of Pragmatic Competence & Number of Participants & Percentage of Participants \\
\hline Native-like & 11 & 21.15 \\
Slightly off, but acceptable & 33 & 63.46 \\
Obviously off & 8 & 15.39 \\
Cannot evaluate & 0 & 0.00 \\
\hline
\end{tabular}

Table 6 presents the descriptive presentation of acculturation attitudes of language learners participating in the study. Descriptive data presented in the table consists of the number and percentage of participants in each acculturation attitude. According to the descriptive data, integration attitude accommodated the highest number of participants (46.15 percent) while marginalization attitude accommodated the lowest number of participants ( 3.85 percent). As the data shows, the majority of participants (61.54 percent) were interested in target language culture adopting assimilation and integration acculturation attitudes whereas the minority of participants (38.46 percent) avoided target language culture adopting separation and marginalization acculturation attitudes.

Table 6. Descriptive Presentation of Acculturation Attitudes

\begin{tabular}{lcc}
\hline Acculturation Attitude & Number of Participants & Percentage of Participants \\
\hline Assimilation & 8 & 15.39 \\
Integration & 24 & 46.15 \\
Separation & 18 & 34.61 \\
Marginalization & 2 & 3.85 \\
\hline
\end{tabular}

Table 7 presents the results of Pearson product-moment correlation coefficient (r) analysis for language learners' level of acculturation attitude and effectiveness of pragmatic instruction. The first thing to consider in correlation analysis is the direction of the relationship between the variables (acculturation attitude and effectiveness of pragmatic instruction). The data shows that there is a positive relationship between the two variables, that is, as level of acculturation attitude increases so too does the effectiveness of pragmatic instruction. The second thing to consider in correlation analysis is the size of the value of the correlation coefficient. This value will indicate the strength of the relationship between the two variables (acculturation attitude and effectiveness of pragmatic instruction). The value of correlation coefficient obtained in the analysis of Pearson product-moment correlation coefficient $(r)$ is 0.70 which according to the guidelines proposed by Cohen (1988) to interpret the values of correlation coefficient suggests quite a strong relationship between level of acculturation attitude and effectiveness of pragmatic instruction. 
IJELS 4(3): 1-7, 2016

Table 7. Correlations

\begin{tabular}{llcc}
\hline & & Acculturation Attitude & Pragmatic competence \\
\hline Pragmatic competence & Pearson Correlation & $0.701^{* *}$ & 1 \\
& Sig. (2-tailed) & 0.000 & 52 \\
& $\mathrm{~N}$ & 52 & $0.701^{* *}$ \\
\hline Acculturation Attitude & Pearson Correlation & 1 & 0.000 \\
& Sig. (2-tailed) & & 52 \\
\hline
\end{tabular}

**. Correlation is significant at the 0.01 level (2-tailed).

To get an idea of how much variance the two variables (acculturation attitude and effectiveness of pragmatic instruction) share, the coefficient of determination was calculated. This can be obtained by squaring the correlation value. The coefficient of determination for the obtained correlation analysis is $\mathrm{r}^{2}=(0.70)^{2}=0.49$ which according to the guidelines proposed by Cohen (1988) to interpret the values of coefficient of determination suggests a very large correlation coefficient. To convert the value of coefficient of determination to 'percentage of variance', it was multiplied by 100 , that is, $\mathrm{r}^{2}=(0.70)^{2} \times 100=49$. This suggests that acculturation attitude helps to explain 49 percent of the variance in language learners' pragmatic competence.

\section{Discussion}

The study found that there is a strong positive relationship between level of acculturation attitude and effectiveness of pragmatic instruction. Pragmatic instruction was more effective for language learners who were more immersed in Australian culture adopting assimilation and integration acculturation strategies than language learners who were more separated from Australian culture adopting separation and marginalization acculturation strategies. Therefore, the null hypothesis of the study which states that there is no relationship between acculturation attitude and effectiveness of pragmatic instruction is rejected.

These findings can be explained through Noticing Hypothesis. Noticing Hypothesis states that "people learn about the things that they attend to and do not learn much about the things they do not attend to" (Schmidt, 2001:30). In order for the input to become intake, the detection of input in the form of awareness and attention is necessary (Schmidt, 1995). Not all input has equal value and only that input which is noticed then becomes available for intake and effective processing (Schmidt, 1990; 2001). Although pragmatic instruction provided for all language learners participating in the study developed their awareness of pragmalinguistic and sociopragmatic differences between target language and their heritage language, most likely only those who were more interested in target language culture tended to notice and pay attention to the pragmalinguistic and sociopragmatic features of the target language to be able to turn the pragmatic input they received during instruction and social interactions into intake.

These findings can be also explained through the level of exposure to target language culture and contact with target language speakers. In the current study, all language learners participating in the study were exposed to target language pragmalinguistic and sociopragmatic features both through pragmatic instruction provided in the class and through outside class interactions with target language speakers. However, language learners who were more immersed in target language culture and had more contact with target language speakers during their academic sojourn definitely had more opportunities to be exposed to target language pragmatic features in order to develop their target language pragmatic competence than language learners who were more immersed in their heritage culture and had less contact with target language speakers.

The findings obtained in this study are consistent with the findings obtained in the studies conducted by Jiang et al. (2009), Cara (2010), and Rafieyan et al. (2015a) who found a strong positive relationship between level of acculturation attitude toward target language culture and level of pragmatic competence. The findings obtained in the current study, however, do not support the findings obtained in the study conducted by Waniek-Klimczak (2011) who found that exposure to authentic culturally specific materials was more useful in developing language learners' language proficiency than formal training they had received in English language classes.

\section{Conclusion}

The study found a significant positive relationship between acculturation attitude and effectiveness of pragmatic instruction. Language learners who were more immersed in the target language culture adopting assimilation and integration attitudes enhanced their target language pragmatic competence during the educational sojourn to a greater extent than language learners who were less immersed in target language culture adopting separation and marginalization attitudes. Therefore, language learners who are on an educational sojourn should be encouraged and provided with opportunities to immerse in target language culture to be able to develop their pragmatic competence to an optimal level (Rafieyan et al., 2015a; Rafieyan et al., 2015b; Rafieyan, 2016).

The study was limited in two ways, however. Firstly, it only investigated the production aspect of pragmatic 
competence and did not include its comprehension aspect. Secondly, the study did not include participants of varying cultural background knowledge to be able to generalize the findings to all language learners from all around the world. Therefore, it is recommended to assess both production and comprehension aspects of pragmatic competence and include participants of varying cultural background knowledge in future studies in order to provide a more comprehensive picture of the relationship between acculturation attitude and effectiveness of pragmatic instruction.

\section{Acknowledgements}

The author would like to acknowledge the contribution of Sahra Siahgolzadeh.

\section{References}

Bardovi-Harlig, K. (2009). Conventional Expressions as a Pragmalinguistic Resource: Recognition and Production of Conventional Expressions in L2 Pragmatics. Language Learning, 59(4), 755-795. http://dx.doi.org/10.1111/j.14679922.2009.00525.x

Berry, D. T. (2001). Development of a New Scale for Measuring Acculturation: The East Asian Acculturation Measure (EAAM). Journal of Immigrant Health, 3(4), 38-55.

Berry, J. W. (1980). Acculturation as Varieties of Adaptation: The Role of Cultural Awareness and Ethnic Loyalty in Acculturation. In A. M. Padilla (Ed.), Acculturation: Theory, Models and Some New Findings (pp. 9-25). Boulder, CO: Westview Press.

Cara, O. (2010). The Acculturation of Russian-Speaking Adolescents in Latvia: Language Issues Three Years after the 2004 Education Reform. European Education, 42(1), 8-36. http://dx.doi.org/10.2753/EUE1056-4934420101

Cohen, J. (1988). Statistical Power Analysis for the Behavioral Sciences. Hillsdale, NJ: Lawrence Erlbaum Associates.

Culhane, S. F. (2004). An Acculturation Interaction Model: Acculturation Attitudes in Second Language Acquisition. Electronic Journal of Foreign Language Teaching, 1(1), 50-61.

Gravetter, F. J., \& Wallnau, L. B. (2013). Statistics for the Behavioral Sciences. Belmont, C A: Wadsworth Publishing. Jiang, M., Green, R. J., Henley, T. B., \& Masten, W. G. (2009). Acculturation in Relation to the Acquisition of a Second Language. Journal of Multilingual and Multicultural Development, 30(6), 481-492. http://dx.doi.org/10.1080/01434630903147898

Kelley, C., \& Meyers, J. (1995). Cross-cultural Adaptability Inventory Manual. Arlington, VA: Vangent.

Landis, J. R., \& Koch, G. G. (1977). The Measurement of Observer Agreement for Categorical Data. Biometrics, 33(1), 159-174. http://dx.doi.org/10.2307/2529310

Pallant, J. (2013). SPSS Survival Manual: A Step by Step Guide to Data Analysis Using SPSS Program (5th ed.). Australia: Allen \& Unwin.

Rafieyan, V., Behnammohammadian, N., \& Orang, M. (2015a). Relationship between Acculturation Attitude and Pragmatic Comprehension. Journal of Language Teaching and Research, 6(3), 504-512. http://dx.doi.org/10.17507/jltr.0603.05

Rafieyan, V., Golerazeghi, H., \& Orang, M. (2015b). Relationship between Cultural Intelligence and Pragmatic Comprehension. Journal of Language Teaching and Research, 6(3). 560-565. http://dx.doi.org/10.17507/jltr.0603.11

Rafieyan, V. (2016). Relationship between Acculturation Attitude and Translation of Culture-Bound Texts. Journal of Studies in Education, 6(2), 144-156. http://dx.doi.org/10.5296/jse.v6i2.9402

Saldanha, G., \& O’Brien, S. (2014). Research Methodologies in Translation Studies. New York, NY: Routledge.

Sam, D. L., \& Berry, J. W. (2010). Acculturation: When Individuals and Groups of Different Cultural Backgrounds Meet. Perspectives on Psychological Science, 5(4), 472-481. http://dx.doi.org/10.1177/1745691610373075

Schmidt, R. W. (1990). The Role of Consciousness in Second Language Learning. Applied Linguistics, 11(2), $129-158$. http://dx.doi.org/10.1093/applin/11.2.129

Schmidt, R. W. (1995). Consciousness and Foreign Language Learning: A Tutorial on the Role of Attention and Awareness in Learning. In R. W. Schmidt (Ed.), Attention and Awareness in Foreign Language Learning (Technical Report No. 9, pp. 1-63). University of Hawaii: Honolulu.

Schmidt, R. W. (2001). Attention. In P. Robinson (Ed.), Cognition and Second Language Instruction (pp. 3-32). Cambridge: Cambridge University Press. http://dx.doi.org/10.1017/CBO9781139524780.003

Taguchi, N. (2013). Production of Routines in L2 English: Effect of Proficiency and Study-Abroad Experience. System, 41(1), 109-121. http://dx.doi.org/10.1016/j.system.2013.01.003

Taguchi, N. (2015). Cross-Cultural Adaptability and Development of Speech Act Production in Study Abroad. International Journal of Applied Linguistics, 25(3), 343-365. http://dx.doi.org/10.1111/ijal.12073

Waniek-Klimczak, E. (2011). Acculturation Strategy and Language Experience in Expert ESL Speakers: An Exploratory Study. Studies in Second Language Learning and Teaching, 1(2), 227-245. http://dx.doi.org/10.14746/ssllt.2011.1.2.4 